\title{
Addressing english reading comprehension difficulties by Somali origin pupils in England primary schools: Using parents as resources
}

\author{
Shamsudin Abikar ${ }^{\mathrm{a}, 1, *}$ (iD) \\ ${ }^{a}$ University of the West of England, United Kingdom \\ ${ }^{1}$ nur2000us@yahoo.com \\ * corresponding author
}

\section{ARTICLE INFO}

Received 2020-07-20

Revised 2021-03-23

Accepted 2021-04-20

Published 2021-04-27

Keywords

EAL

Somali origin pupils

Reading comprehension

Parental involvement

England education policy

\section{ABSTRACT}

The question of whether classroom reading activities in primary schools in England can be solely relied on to be sufficient for English as additional language (EAL) pupils to comprehend English text was the focus of the paper. Two case studies where Somali origin EAL pupils involved in learning English reading comprehension were utilized as a springboard to develop my argument that parents are an intrinsic part of developing pupils' English comprehension as they may constitute financially less expensive and rich resources in terms of cultural experiences. Furthermore, England's education policy regarding EAL pupils, reading for comprehension, and factors that influence it: vocabulary knowledge, teacher -students ratio in England school and parental involvement in schools were explored to provide an answer for the question of whether only reading for comprehension activities in the classroom is enough to promote the understanding of EAL Somali origin. It was argued that only those activities are not sufficient, and there is a need for the use of parents as resources to enrich the text input, which potentially increases the comprehension skills of Somali origin EAL pupils.

This is an open access article under the CC-BY-SA license.

\section{Introduction}

More than 1 million bilingual children are between 5-16 years in English schools [1]. This means that these children learn English as an additional language (EAL). The EAL population are growing in number, especially those in primary school with different levels of English proficiency upon starting schools. Similarly, the Somali origin pupils feature part of the EAL pupils in England [2]. The presence of Somalis in the UK began in the 19th Century with their arrival on merchant ships; however, waves of Somalis began coming to the UK in the late 1980s and early 1990s as the consequence of the Somali civil war [3]. Children of the newly arrived parents attend the UK mainstream schools where the medium of instruction is English. A common trend that literature attribute to Somali origin pupils' underachievement in school is their lack of academic language proficiency. For instance, a report, why do Somali Pupils Achieve Lower Grades in School? Conducted by Mousa for the African Educational Trust and Evelyn Oldfield Unit Report in 2012, aimed to explore the underlying factors behind Somali pupils' underachievement. It was found that the main reason for Somali pupils' underachievement was the language barrier experienced by pupils. Thus, from these findings, it can be inferred that extra reading support may be effective in remedying the language barriers and enhance the comprehension skills of these pupils. Inevitably, this raises the question: can classroom reading activities be solely relied upon to challenge the English as an 
additional language (EAL) learners of Somali origin's English reading comprehension difficulty in England primary classrooms?

Despite possessing the ability to decode and understanding the meaning of a word in a sentence, it can often be the case that some English as additional language learner students in primary schools are unable to comprehend the meaning. A search of the literature shows that, despite adequate decoding skills, a handful of children learning English as an additional language (EAL) show reading comprehension difficulties [4]. Similarly, Burgoyne et al. published a paper that focused on the comprehension skills of children learning English as an additional language however, their account was limited to contribute to the lack of comprehension due to the lower levels of English vocabulary knowledge despite the existence of other factors that hinder the comprehension in the classroom [5]. I argue here that understanding a text in a non-home language by Somali origin EAL pupils in England primary schools require a cultural perspective to embed conceptual understanding. Thus, parental involvement in text selection or preplanning the reading text can be important for pupils' comprehension. The rationale for this is because the EAL pupils' time in school is insufficient for them to cope with the comprehension skills needed for academic attainment, but parents need to be used as resources to contribute when choosing classroom reading texts.

My argument here will be developed by discussing the factors in classroom and school- home relationship that positively contribute and act as vital in developing the classroom reading comprehension. This is because, the literature emphasized the importance of a positive school- home relationship for children's academic attainment. The history of parental involvement, Campbell and Palm, can be traced back to the early 19th century '.. when a group of [middle class] mothers in New England formed maternal association...[that] met and discussed issues such as discipline and moral training [6].' This indicates that the understanding of the parental role in school began long ago with the view of pupils' academic attainment. In the context of the UK, developing the EAL pupils' English reading comprehension is important because, The Telegraph, 2015, noted that, as UK schools are educating an increasing number of students with English as an additional language, teachers have limited time and resources to deal with these students. As communication misunderstanding may arise due to the results of people bringing different perspectives to the words they use for communication [7], definitions of key terms are provided here: English as Additional Language (EAL) pupils are regarded here to be the 'advanced bilingual learners' and 'children new to English' [8]. Therefore, this also applies to Somali second-generation students from an established Somali community. The term Parents is meant by parents of the EAL pupils who share ethnicity with the Somali EAL pupils.

\section{Method}

The Somali community in the United Kingdom is one of the largest and long established in UK [3], [9], and their arrival in the UK dates back to the 19th century [3], [10]-[13]. Yet, this society which is everywhere in the UK is neglected and remain invisible [9]. For example, the ticking bomb: The Educational Underachievement of Somali Children in British Schools, notes that as a consequence of failing to recognize Somalis as a distinct ethnic group, they remain ignored and their needs neglected by the local and national policy-makers [14], [15]. Another fact that exacerbates the identification of Somali origin pupils as a distinct ethnic group can be the jargon used when presenting school attainment data. For example, EAL Students [16]; ethnic minority- black Africans [17]. These identifications make it difficult to observe and track the attainment of Somali ethnic pupils in England schools. Research that explored the attainment of Somali origin pupils was a report entitled drivers and challenges in raising the achievement of pupils from Bangladeshi, Somali and Turkish backgrounds which focused on why attainment rates amongst Bangladeshi pupils have significantly improved over recent years while Turkish and Somali pupils continue to perform below the national average [18]. A reason given for the Somali pupils' poor performance by the Report was because of their lack of English comprehension and use of academic language. Thus, it undoubtedly can be the case that due to lack of identifying the Somali EAL pupils as an ethnicity on its own negatively contributes to less monitoring in terms of their attainment. Also, it can be understood that the poor performance due to lack of English comprehension can be challenged by providing the Somali EAL pupils with extra input in the form of their native language (Somali).

The case study method is used in this study. Case study research has grown in popularity as a methodology in educational research in recent years. This could be due to a variety of factors, 
including an increased interest in all forms of qualitative research as well as the proliferation of case studies used in education classes.

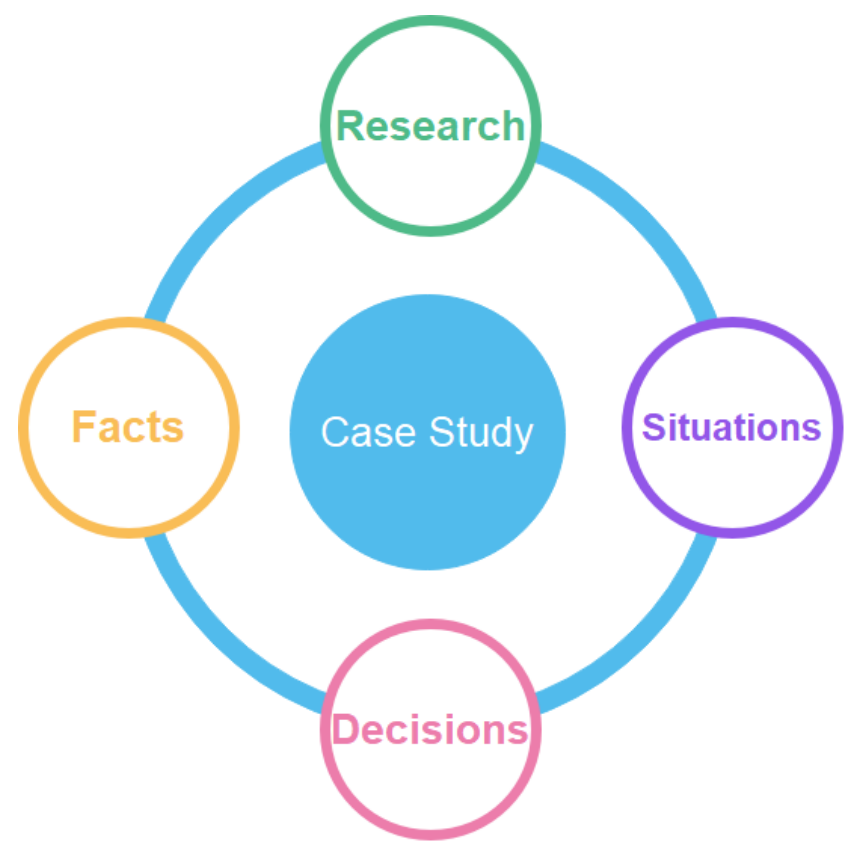

Fig. 1. Scope of case studies in educational research

Case studies, which are used for pedagogical purposes, are inspired by case study research. They tell the story of a specific educational event in context so that new teachers can understand the complexities of analysis and possible solutions. Case studies, as a research method, analyze a specific set of issues within the educational context and could easily be used in narrative form to serve as the foundation of a pedagogical tool (see fig 1). A case study was created in this study to examine addressing English reading comprehension difficulties by Somali origin pupils in England primary schools: using parents as resources [19].

\section{Results and Discussion}

\subsection{Case Studies of EAL Somali Pupils Learning English}

This study uses case studies. Case study research methodologies are defined as empirical investigations that investigate contemporary phenomena in the context of real life, when the boundaries between phenomena and contexts are unclear, and when multiple sources of evidence are used. The case studies in the results of this study are cases of EAL Somali Pupils Learning English.

First, case study 1, Ahmed (pseudonym) was a 7-year-old boy in a primary school in Bristol, England. He was admitted to a Year 3 classroom in Bristol in 2009 after arriving from Somalia with his siblings (an older brother and a younger sister). Together with their mother they reunited with their father who was in Bristol. He, in a small group of 4 students, began learning English by participating in a Read and Write Inc. program, mainly sounding but also structuring sentences and their comprehension (for further details see: https://www.ruthmiskin.com/en/programmes/phonics/). I co-taught the program with a British native colleague. On an occasion when the group progressed, as my colleague was teaching, the group was asked whether the sentence: the dog jumps over the log makes sense. They all reached a consensus that it was. Then, my colleague jumbled the sentence: the log jumps over the dog; then, they all except Ahmed said it did not make sense. My colleague thought that Ahmed did not understand the sentence and attempted to continue. However, I intervened by excusing and asked Ahmed again whether the sentence made sense to which he affirmed. After using the Somali language to translate the sentence from English to Somali, I, once again, asked Ahmed whether he would change his opinion. To my surprise, he remained adamant. Then, I requested him to explain. By recounting in the Somali language, he explained me 'at the park, people throw 
stick over the dogs and the dogs chase the stick. Thus, the log jumps over the dog is right.' I was completely mesmerized by his answer and translated what he told me to my colleague.

Second, case study 2, for many years, I have been supporting a group of Year 6 with their English comprehension skills. Most of the time, I have used Schofield \& Sims Key Stage 2 Books Comprehension by the author Celia Warren. These books have been available at my school and they are, in my view, organized in a clear, simple, and yet challenging manner to develop the comprehension. Once, after spending time with the text: A great Strom in Scotland, a fiction story in Book 1 of Schofield \& Sims Key Stage 2 Books Comprehension, questions were to be answered to assess the comprehension of the text. To my surprise, when planning the lesson, I was bewildered to understand, let alone answer, the question: 'If Grumble' really was Grandfather's name, what change would you make to the sentence " all you ever do is grumble, grumble?" Children also found it challenging. The answer is: all you ever do is grumble, Grumble. The last grumble, the ' $G$ ' should be a capital letter to indicate that it is a name. Despite my knowledge relating to how to form a capital letter and understanding the text where the grandad has been referring to grumble, my failure to provide an answer for the question can be attributed to a fact which relates to my culture: respecting the elders which escaped from my attention.

\subsection{England's EAL Education Policy}

The England's Department for Education (DFE) [20] Statutory guidance, in terms of National curriculum in England: framework for key stages 1 (5 to 7 years) to 4 (14 to 16 years), prescribes that teachers should develop pupils' spoken language, reading, writing and vocabulary as a salient aspect of the teaching of every subject. This with the view that fluency in the English language is an essential foundation for success in all subjects. Under the 4.5 and 4.6 Sections, the DFE [21] focused on special arrangement that should be made for pupils learning English as an additional language:

Teachers must also take account of the needs of pupils whose first language is not English. Monitoring of progress should take account of the pupil's age, length of time in this country, previous educational experience, and ability in other languages' (Section, 4.5).

The ability of pupils for whom English is an additional language to take part in the national curriculum may be in advance of their communication skills in English. Teachers should plan teaching opportunities to help pupils develop their English and should aim to provide the support pupils need to take part in all subjects' (Section, 4.6).

Although Section 4.6 is helpful for developing the EAL pupils' English competence, it seems that teachers are left helpless to support pupils with whom they share neither language nor culture. Additionally, this may also indicate that the EAL pupils' academic attainment outcome at an early stage of English acquisition is less secure. This can be attributed to the fact that an alien language in the form of medium instruction is employed to make sense of this same alien language which is also used for the content of the curriculum. This will potentially lead to inequality in classroom learning and can further cause academic underachievement.

\subsection{Reading Comprehension}

Prior to dealing with comprehension, it is crucial to reflect on what reading is. Reading can be understood as the interaction that occurs between the reader and the text. Tennent explains that, as human beings, we are not 'hard-wired' to read [22]. This mean that reading does not happen automatically, and the reader needs to be taught how to read. Tennent further explains that the reading is a process that requires word recognition and linguistic comprehension. To simplify the two phrases word recognition and linguistic comprehension, the first may refer to the ability of decoding the word whereas the latter can be the understanding of the whole sentence in the sense of Stothard and Hulme [23].

According to the authors, the skilled reader needs to first identify the words in a text and integrate their meanings into sentences to comprehend what they are reading. This clearly signals knowledge of vocabulary (the meaning of the words) and integrating them with the sentence is what causes the 
comprehension of a text. However, the assumption that children's good reading skills lead to good comprehension because of two reasons: 1) their comprehension problem does not become apparent before their third or fourth year of schooling whilst all the time such children are perceived as good readers; and 2) the material required from them to understand is not demanding in terms of language comprehension during that period [24]. Benchmark emphasized that the evidence for a relationship between fluency and comprehension is strong due to 1) when the learner reads aloud effortlessly and recognizes most words automatically; 2) when the learner, while constructing the meaning, integrates all elements effortlessly and simultaneously [25]. This is not as straightforward as it seems to be for all pupils because for bilinguals, fluency reading is a challenge for two reasons: 1) it requires automatic word recognition as they display slower lexical access and smaller receptive vocabularies; 2) despite adequate decoding skills, bilingual readers display poor reading comprehension.

\subsection{The Importance of Vocabulary Knowledge in Comprehension}

The crucial role of vocabulary for the learning is well documented in the literature [26]-[30]. In the context of England study of the contribution of general language ability, reading comprehension and working memory to mathematics achievement among children with English as additional language (EAL), aimed to understand how language ability, reading comprehension and working memory contribute to mathematics achievement among children with English as an additional language (EAL) [30]. It raised the argument that as the skills needed for solving mathematical problems become daily reality, learning the language used in mathematics such as mathematical jargons and abstracts is important. However, this learning should also include vocabulary learning since problems arise when the gap between mathematical jargons and abstracts, and vocabulary knowledge becomes blurry. The study offered a lexically ambiguous term as an example: the word ' $o d d$ ' which can be assumed to describe something that is strange in the context of the language used daily, but in mathematical terms it is expected to be understood as '.. in relation to numbers... to describe any integer that cannot be divided exactly by two. This clearly emphasizes the important role of the mathematic learner's vocabulary knowledge for the reading comprehension skills.

\subsection{The Importance of Prior Knowledge in Comprehension}

Prior knowledge is what an individual already knows as it serves as providing '...the platform, the schema, and vocabulary need to succeed [31] because it is a strategy [32] which can be used for enhancing the learner's comprehension skills prior to engaging with any topic by modifying, transferring and reintegrating the past experience to the text [33]. Fountas and Pinnell developed a graphic wheel named Systems Of Strategic Action (SOSA) [34] with twelve categories which come under three main ways of thinking: 1)thinking within the text: according to the authors, by engaging this strategy, the reader acquires the ability to search for and use information, to monitor and self-correct, to solve words, to maintain fluency, to adjust and summarize the text; 2) thinking beyond the text: this strategy enables bringing prior knowledge and understanding of how the world works to the text. Since it promotes making informed predictions, making meaningful connections between the content of the text and their own life experience, other texts, and the whole world. Accordingly, it enables synthesizing information for further incorporating new understandings and allows inferences to be made about what the author means not expressing explicitly; and 3) thinking about the text: this strategy refers to thinking about the text and enables the reader to identify how the text is structured and crafted by the writers. An important point is raised in 2) which is having a prior knowledge and understanding of how the world works. This is not always the case for every pupil because 1) if the pupil is a poor reader and their text comprehension is less developed, they are unlikely to possess prior knowledge on how the world works; 2) due to socioeconomic circumstances, many pupils are unable to relate what they are reading to their experience of the world.

This is more evident among others when the economically less-well pupils are engaged in text about holidays: travelling in airplanes, preparing holiday suitcases, activities in airports. Another crucial point on why pupils fail to activate their prior knowledge of the text may relate to the fact of their subtractive bilingualism status although this concept is critiqued by some scholars such as Pliiddemann [35] Flores [36] that they might have experienced because of transiting home-language to school-language (medium of instruction). According to Baker, subtractive bilingualism may occur when the second language is acquired '... with pressure to replace or demote the first language...[and can be ] relate [d] to a less positive self-concept' of the learner [37]. 


\subsection{Teacher Students Ratio in England School}

Class size can be an important factor for student's academic attainment. Perlman et al. argued that adequate teacher -student ratios improve the student's outcome through providing extra opportunities for individual interactions and thus is a key quality that serves as an indicator for early childhood education and care programs [38]. Moreover, Peers explains that class size debate can be approached from two perspectives: that of an economist and an educational researcher although both can be bridged by adopting a broad perspective: that any attempt to increase the class size will result in less opportunity to support individual learning [39]. Similarly, a Report from the England's Department for education noted that evidence shows that positive impact in terms of attainment and behaviour entail where the class size remains small as individual students remain to be the focus of the teacher's attention. The Report continued to point out that the number of children born in England each year had been rising and that it was projected to continue to be rising. This means that the DFE has been in anticipation of larger class size which, if became true, would revert the positive attainment and behaviour. This turned to be the case when DFE highlighted that since 2009 there were 727,000 more students in schools with EAL student number also increasing over recent years. This increase clearly can be understood as that as the class size becomes larger, pupils learning English as an additional language (EAL) would need far more teacher attention than native students whose first language is English; and that without this special attention the EAL pupils' attainment may suffer immensely.

\subsection{The Importance of Parental Involvement in Learning}

Hallgarten explained that what creates a successful home-school relationship is an effective twoway communication between parents and school staff [40]. Kearney postulates that ethnic difference in terms of parental involvement has been the focus of the researchers [41]. Furthermore, they note that central to the problem of school-parent misunderstanding is that teachers often receive less training on how diverse family lifestyles, cultural backgrounds, and their values are which characterize many of their students. Finally, they concluded that this can be a cause of inappropriate academic practice based on the view of stereotype or traditional European-American culture. Similarly, Christine and Matthiesen's study painted the picture of how teachers at Danish public schools and their principals conceptualize the Somali diaspora's parenting practices and how that affects their interaction with the children in classrooms and the home-school communication [42]. Their study observed that the teachers and principals used a deficit logic to make sense of Somali diaspora parental practices. The study concluded by explaining that this negative perception led to 1) either teachers allotting valuable time to attempt to educate parents, or 2) compensate for the perceived deficiencies.

To support teacher's development of a functional metalanguage for middle years discipline literacy instruction, Humphrey used the model [43], teaching and learning cycle, developed by Callaghan and Rothery which aims to '...provide a powerful resource for scaffolding literacy development [44].' According to Victoria State Government the model consists of four interrelated stages such as building the context of what is to learn; deconstruction of the text by focusing on the structure and the language of the text, how language choices work to shape meaning; teacher and students jointly constructing the text and then students are given the opportunity to independently write of the genre [43], [45], [46]. This clearly shows that the teaching methodology is far from being a granted process where pupils can always comprehend the teacher's input but rather consider different factors that affect the learning.

The importance of a positive home-school relationship and how it is crucial for teachers to be equipped with the understanding of pupils' cultural background in order to promote EAL pupils' learning as well as a sound relationship with parents [40]-[42]. The teaching and learning cycle used by Humphrey [43] undisputedly explains the importance of constructing and deconstructing the text and scaffolding the learners to improve the outcome of the reading and writing. This potentially means that an individual with cultural knowledge can be in a position to support the construction and deconstruction of a text as, explains that there is a difference between the thinking patterns of the students and that of the teacher when they do not share the same cultural background [47]. 


\section{Conclusion}

This paper argued the importance of involving parents in the planning stage of English language texts in classrooms to promote the comprehension of EAL Somali origin pupils in England primary schools. First, the context of Somalis Pupils in the UK was explained to flag out the challenge they face, which was the understanding of English. Case Studies of EAL Somali pupils learning English were presented to illustrate the reality in classrooms and how it is important to use pupils' first language to understand the second language (English) they were acquiring. However, in England there is no clear policy which instructs the teaching of First Language in the classroom; and the EAL policy noted in this paper seems to be rather vague in that supporting a Second Language with a Second Language with the view of attaining a successful outcome may be delusional. Also, some aspects that are essential for the comprehension of English texts were elaborated. Moreover, how the EAL pupils benefited special teacher focus was illustrated. Finally, the importance of building a sound relation between home-school relationships was explained. Synthesizing all sections of the paper potentially points to one direction: the classroom reading activities alone cannot be relied upon to challenge the EAL Somali origin pupils' English reading comprehension difficulty in England primary classrooms. Thus, this paper argues for schools to use parents as resources to support comprehension because they are less expensive resources. They may be able to provide a conceptual understanding of English vocabularies and can be able to activate the pupil's prior knowledge.

\section{Acknowledgment}

The authors would like to thank University of the West of England, United Kingdom, for the granted supports. Furthermore, thanks to all participated for their participation in this study.

\section{Declarations}

Author contribution $\quad$ : SA: Conceptualization, methodology, writing, reviewing, and editing.

Funding statement $\quad:$ No funding was made available for this research.

Conflict of interest $\quad:$ The authors declare no conflict of interest.

Additional information : No additional information is available for this paper.

\section{References}

[1] N. A. for L. D. in the C. (NALDIC), "The latest statistics about EAL learners in our schools," 2013. http://www.naldic.org.uk/research-and-information/eal-statistics/ (accessed Mar. 29, 2021).

[2] C. Dixon, J. Thomson, and S. Fricke, "Language and reading development in children learning English as an additional language in primary school in England," J. Res. Read., vol. 43, no. 3, pp. 309-328, 2020, doi: 10.1111/1467-9817.12305.

[3] O. S. Foundation, At Home-Somalis in London-Somalis in European Cities. New York: Open Society Foundation, 2014.

[4] C. Bowyer-Crane, S. Fricke, B. Schaefer, A. Lervåg, and C. Hulme, "Early literacy and comprehension skills in children learning English as an additional language and monolingual children with language weaknesses," Read. Writ., vol. 30, no. 4, pp. 771-790, 2017, doi: 10.1007/s11145-016-9699-8.

[5] K. Burgoyne, J. M. Kelly, H. E. Whiteley, and A. Spooner, "The comprehension skills of children learning English as an additional language," Br. J. Educ. Psychol., vol. 79, no. 4, pp. 735-747, 2009, doi: 10.1348/000709909X422530.

[6] R. Leitch and C. Day, "Action research and reflective practice: towards a holistic view," Educ. Action Res., vol. 8, no. 1, pp. 179-193, Mar. 2000, doi: 10.1080/09650790000200108.

[7] R. M. Thomas and D. L. Brubaker, "Theses and Dissertations: A Guide to Planning, Research, and Writing. America." Greenwood Publishing Group, Inc, 2000, available at: Google Scholar.

[8] J. Conteh, The EAL Teaching book: Promoting success for multilingual learners. Learning Matters, 2015, available at: Google Scholar. 
[9] M. Kahin and C. Wallace, Somali Parents and Schooling in Britain. ERIC, 2017, available at: Google Scholar.

[10] D. Robinson and A. Ambrose, "New migration, neighbourhood effects and community change," 2011, available at: Google Scholar.

[11] N. A. Kabir, Young British Muslims: Identity, Culture, Politics and the Media: Identity, Culture, Politics and the Media. Edinburgh University Press, 2010, doi: 10.3366/edinburgh/9780748641338.001.0001.

[12] A. O. Farah, Transnationalism And CivicEngagement. Adonis \& Abbey Publishers Ltd, 2012, available at: Google Scholar.

[13] A. Ahmed, “100 Years After Somalis Arrive in London, It's High Time to Learn About Them,” 2014. https://www.opensocietyfoundations.org/voices/100-years-after-somalis-arrive-london-it-s-high-timelearn-about-them (accessed May 10, 2020).

[14] F. Demie, K. Lewis, and C. McLean, Raising the Achievement of Somali Pupils. Lambeth Research and Statistics Unit, 2007, available at: Google Scholar.

[15] A. A. Okore, “The Impact Of Socio-Economic And School Factors On The Academic Performance Of Secondary Students In Kibera Slums, Nairobi County, Kenya.” University of Nairobi, 2018, available at: Google Scholar.

[16] S. Strand, L. Malmberg, and J. Hall, "English as an Additional Language (EAL) and educational achievement in England: An analysis of the National Pupil Database,” 2015, available at: Google Scholar.

[17] L. Stokes, H. Rolfe, N. Hudson-Sharp, and S. Stevens, "A compendium of evidence on ethnic minority resilience to the effects of deprivation on attainment," London Dep. Educ. Res. Rep., 2015, available at: Google Scholar.

[18] S. Strand et al., "Drivers and challenges in raising the achievement of pupils from Bangladeshi, Somali and Turkish backgrounds," London, DCSF, 2010, available at: Google Scholar.

[19] K. Grauer, “A Case for Case Study Research in Education,” in Action Research Methods, New York: Palgrave Macmillan US, 2012, pp. 69-79, doi: 10.1057/9781137046635_4.

[20] N. Roberts, "The school curriculum in England," 2021, available at: Google Scholar.

[21] D. for Education, "Statutory guidance National curriculum in England: primary curriculum," 2015. https://www.gov.uk/government/publications/national-curriculum-in-england-primary-curriculum (accessed Nov. 04, 2017).

[22] W. Tennent, Understanding reading comprehension: Processes and practices. Sage, 2014, available at: Google Scholar.

[23] S. E. Stothard and C. Hulme, "A comparison of reading comprehension and decoding difficulties in children," Read. Compr. difficulties Process. Interv., pp. 93-112, 1996, available at: Google Scholar.

[24] J. Oakhill, K. Cain, and C. Elbro, "Reading comprehension and reading comprehension difficulties," in Reading Development and Difficulties, Springer, 2019, pp. 83-115, doi: 10.1007/978-3-030-26550-2_5.

[25] P. Benchmark, Reading Assessment Resources, Titles and Test Types Levels 1-14 Toronto. Toronto: Nelson Education, 2018.

[26] T. V Rasinski, Building Vocabulary From Word Roots Student Book Lv 8 (4c): 4 Color Book. Teacher Created Materials, 2007, available at: Google Scholar.

[27] M. C. Grant, D. Fisher, and D. Lapp, Reading and writing in science: Tools to develop disciplinary literacy. Corwin Press, 2015, doi: 10.4135/9781483393322.

[28] I. L. Beck, M. G. McKeown, and L. Kucan, Bringing words to life: Robust vocabulary instruction. Guilford Press, 2013, available at: Google Scholar.

[29] R. D. Silverman, C. P. Proctor, J. R. Harring, A. M. Hartranft, B. Doyle, and S. B. Zelinke, "Language skills and reading comprehension in English monolingual and Spanish-English bilingual children in grades 2-5," Read. Writ., vol. 28, no. 9, pp. 1381-1405, 2015, doi: 10.1007/s11145-015-9575-y. 
[30] M. T. Farrugia and N. V. Trakulphadetkrai, "Maltese teachers' beliefs concerning the integration of children's literature in mathematics teaching and learning," Cogent Educ., vol. 7, no. 1, p. 1817253, 2020, doi: 10.1080/2331186X.2020.1817253.

[31] E. Jensen and L. Nickelsen, Deeper learning: 7 powerful strategies for in-depth and longer-lasting learning. Corwin press, 2008, available at: Google Scholar.

[32] G. H. Gregory and T. Parry, Designing brain-compatible learning. Corwin Press, 2006, available at: Google Scholar.

[33] M. Day, Assessment of Prior Learning: A practitioner's guide. Nelson Thornes, 2002, available at: Google Scholar.

[34] I. C. Fountas and G. S. Pinnell, Guiding Readers and Writers, Grades 3-6: Teaching Comprehension, Genre, and Content Literacy. ERIC, 2001, available at: Google Scholar.

[35] P. Pliiddemann, “Additive'and'subtractive': Challenges in education for multilingualism,” Per linguam, vol. 13, no. 1, 1997, doi: 10.5785/13-1-197.

[36] O. García, N. Flores, and M. Spotti, The Oxford handbook of language and society. Oxford University Press, 2017, doi: 10.1093/oxfordhb/9780190212896.001.0001.

[37] C. Baker, Foundations of bilingual education and bilingualism. Multilingual matters, 2011, available at: Google Scholar.

[38] M. Perlman, B. Fletcher, O. Falenchuk, A. Brunsek, E. McMullen, and P. S. Shah, "Child-staff ratios in early childhood education and care settings and child outcomes: A systematic review and meta-analysis," PLoS One, vol. 12, no. 1, p. e0170256, 2017, doi: 10.1371/journal.pone.0170256.

[39] C. Peers, Class Size and Pupil? Teacher Ratios: Where Education and Economics Collide. IAP, 2016, available at: Google Scholar.

[40] J. Hallgarten, Parents Exist, OK!?: Issues and visions for parent-school relationships. Institute for Public Policy Research, 2000, available at: Google Scholar.

[41] C. Kearney, Helping school refusing children and their parents: A guide for school-based professionals. Oxford University Press, 2008, available at: Google Scholar.

[42] N. C. L. Matthiesen, "Working together in a deficit logic: home-school partnerships with Somali diaspora parents," Race Ethn. Educ., vol. 20, no. 4, pp. 495-507, 2017, doi: 10.1080/13613324.2015.1134469.

[43] S. Humphrey, Academic literacies in the middle years: A framework for enhancing teacher knowledge and student achievement. Taylor \& Francis, 2016, doi: 10.4324/9781315625584.

[44] M. Callaghan and J. Rothery, Teaching factual writing: a genre-based approach: the report of the DSP Literacy Project, Metropolitan East Region. Metropolitan East Disadvantaged Schools Program, 1988, available at: Google Scholar.

[45] B. Derewianka and P. Jones, Teaching language in context. ERIC, 2016, available at: Google Scholar.

[46] S. Humphrey and S. Feez, "Direct instruction fit for purpose: Applying a metalinguistic toolkit to enhance creative writing in the early secondary years," Aust. J. Lang. Literacy, vol. 39, no. 3, pp. 207-219, 2016, available at: Google Scholar.

[47] J. D. Trubon, Blending Cultures: A Guide for Esl Teachers and Students. iUniverse, 2011, available at: Google Scholar. 